\title{
Vocabulary in the New B.Ed. General English under Tribhuvan University
}

Binod Luitel

\begin{abstract}
This paper reports a study on the curricular policy direction regarding vocabulary instruction, and the characteristics of words focused in the course books of General English for B.Ed. under Tribhuvan University. The research aimed at linguistic analysis of items, their frequency in general use, their usefulness considering the students' career prospect, and the nature of their occurrence in course materials. The focus offered to vocabulary component in the course is found reasonably high; frequent vocabulary items focused for learning in the books are more than infrequent ones; and about two-thirds of the focused words are useful while the remaining one-third are not so useful for students. Out of the two course books used for vocabulary teaching, 'Academic Vocabulary in Use' has offered much more appropriate lexical content than 'New Generation English'.
\end{abstract}

\section{Key words: Frequency, Word class, Word structure, Glossary, Exercise}

\section{Introduction}

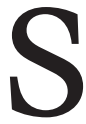
ince vocabulary is an essential component of language, its teaching-learning inevitably deserves attention in the context of English as a foreign language. So, it would be highly relevant to study the treatment of vocabulary in the newly introduced courses of General English offered to the students of B.Ed. under Tribhuvan University (TU). Such a study will be useful towards appraising the credibility of course materials in addressing the learners' needs.

\section{Literature review}

\section{Word}

Many people tend to identify words simply by the space between the strings of letters in written language. In computational analysis, Ku era and Francis (1967, p. xxi) had adopted the definition of word as "the string of letters separated by space as appeared in the corpus". But, from a deeper perspective, we need to recognize words at different levels after understanding the concepts introduced below.
Token and type: 'Token' means the exact running word form in a text, whereby each occurrence of a form is counted separately. When we say that a text has 3000 running words, it means there are 3000 tokens. If we consider 'type', only the word form that is 'different' from all the remaining ones is counted (Read, 2000). If 'sit' occurs in a text 10 times, these are the 10 tokens of the same type; but 'sits' is a type different from 'sit'.

Lemma: It is the group of related word forms which differ by inflection. Following Read (2000, p. 18), “...the base and inflected forms of a word are collectively known as a 'lemma'." Thus, the items 'jump', 'jumps', and 'jumped' make the same lemma.

Family: A word family includes a base word, all its inflected and regularly derived forms (Nation and Waring, 1997), whereby all the related word forms share a common meaning (Read, 2000, p. 19), though the individual members have their own specific meanings. So, the forms 'calculate', 'calculates', 'calculation' and 'calculator' are grouped under the same word family. 


\section{Word frequency}

Some words occur frequently in language, while others occur rarely. A small size of very frequent words covers a substantially vast amount of language use. Following Nation (1994), the first 2,000 high-frequency word families cover about $87 \%$ of written and $95 \%$ of spoken corpus. Adolphs and Schmitt (2003) also found 2,000 word families covering about $95 \%$ of spoken English. Laufer (1997a) reported that 3000 word families would cover $90 \%-95 \%$ of any written text.

Since high-frequency words occur most of the times, learners can grasp language very comfortably after mastering them. But teaching low-frequency items without introducing the highfrequency ones will be less relevant, since learners rarely find such items in use outside their course materials. Thus, word frequency information is highly relevant in deciding the vocabulary items to be included in course materials, if we want to develop "a survival-level repertoire for comprehension and production" in learners (McCarthy, 1990, p. 79).

In the finding of Meara and others (1997), 89\% of the total language use in classroom was covered by high-frequency words but less frequent items covered only $3 \%$ - which implies that learners will be facilitated a lot to understand classroom proceedings after they master the high-frequency words. McGregor (1989) found that, whenever learners face difficulty in comprehending a reading text, their problem can be remedied if the text is presented to them after simplifying it by using the high-frequency words, as learners understand the more frequent words faster and more accurately than the less frequent ones (Wang and Koda, 2005, p. 89). Thus, placing focus on the high-frequency words is justified not only on the ground of their coverage in language, but also for accelerating the process of language learning.

However, there is the trend of preparing course materials simply on the basis of writers' intuition regarding which items/s would be important, rather than on word frequency information (Biber and Reppen 2002, cited by Johnstone, 2003).

\section{Lists of frequent English words}

There have been various attempts of estimating the frequency of words in English. Dictionaries have also included the information on word frequency in the entry. Some of the attempts of listing words on the basis of frequency counts made in the recent years are mentioned below.

- Longman dictionary-derived list, 2003: In Longman Dictionary (Pearson Education Limited, 2003), the 3000 most frequent headwords have been indicated in the entry with red colour. These headwords have been symbolized 'S1', 'S2', 'S3', 'W1', 'W2', and 'W3' - whereby 'S' stands for 'spoken English' and 'W' for 'written English'. The number ' 1 ', '2', and ' 3 ' indicate the frequency band that the given word falls in: the first 1000 word level, 1000-2000 word level, and 2000-3000 word level respectively.

- Collins COBUILD dictionary-derived list, 2006: Collins COBUILD Dictionary (Sinclair et al., 2006) has indicated word frequency in the entry using 4 frequency bands, whereby the most frequent words are marked with three diamonds (»), the next most frequent ones with two ( $\bullet)$, still less frequent with one $(\diamond)$; and the infrequent words have not been marked.

- Cambridge dictionary-derived list, 2008: In Cambridge Dictionary (Walter et al., 2008), the most frequent words have been signaled with 'E' (Essential), 'I' (Improver) and 'A' (Advanced), occurring more than 400 times, 200-400 times and 100-200 times per 10 million words respectively.

- Collins COBUILD dictionary-derived list, 2009: In this dictionary (Heinle Cengage Learning and Harper Collins, 2009), the frequent words have been symbolized in the same way as done in its earlier version - i.e. by three, two or one diamond () after the entry. The frequency count is based on 'The Collins Bank of English'.

- Oxford dictionary-derived list, 2010: The Oxford Dictionary (Hornby, 2010) has indicated the 3000 key words of English including the most frequent ones. These items have been symbolized with a key after the entry.

\section{Usefulness of words}

While a greater emphasis on frequent words 
is justified in the elementary and school level instruction, mere dependence on frequency can cause limitation in language learning for college students. Following $\mathrm{Hu}$ and Kelly (2004, p. 21), “...beyond the 3,000 word level, there is no way of applying the criterion of frequency as words probably do not occur more than once in a million." In such cases, the criterion of usefulness deserves equal attention in vocabulary selection for teaching.

Despite the greater coverage of the 2000 most frequent words in English, it has been stressed that they carry less information content in reading texts, while a great deal of information is contained in the items that are not so frequent (Richards, 1974). Such items also deserve attention in teaching, because comprehension can be distorted without knowing them.

We can decide the usefulness of particular vocabulary item/s based on learners' needs. University students specializing in education, for instance, need to be familiar with the terms that occur in educational discourse; therefore, such items could be highly relevant and useful for them considering their career prospect. Moreover, academic vocabulary and defining vocabulary deserve special consideration in teachinglearning, which are introduced below.

\section{Academic vocabulary}

Since the purpose of learning English is mostly academic for the students of higher level, learning of word-meanings used in academic context has a great importance. There have been some attempts of listing out academic words in English. For instance, Oxford academic word list (Hornby, 2010) has been developed by analyzing the occurrence of words in a corpus of academic texts containing several subject areas. This list has 570 word families covering $10 \%$ of written academic texts. Similarly, Coxhead (2000) has presented a list of 570 headwords based on a corpus of 3513330 tokens, 70377 types and 414 academic texts. In the same way, Collins COBUILD academic word list (Heinle Cengage Learning and Harper Collins, 2009) has 570 word families.

\section{Defining vocabulary}

This term means "a basic list of words with which other words can be explained or defined" (Richards et al., 1985). Such words are used particularly to produce dictionaries. In addition to the high-frequency items, words having 'core meaning' are also used as the defining vocabulary. Since a core word gives the 'core' meaning of a cluster of semantically synonymous items, it tends to have a greater possibility to function as the defining word (Carter, 1987a). For example, 'eat' can be considered the core word in the list of 'gobble', 'dine', 'devour', 'eat', and 'stuff'; so 'eat' will be suitable to explain the meaning of others while others are unlikely to be used for defining 'eat'. These words are used to achieve simplicity in learning. Learners tend to favour the use of such vocabulary items (MacFarquhar and Richards 1983, cited by Carter, 1987b), as such items are close to their learning standard.

\section{The present study}

Considering the importance of more frequent and useful vocabulary items, the study was initiated with a view to examine the vocabulary content focused in General English of B.Ed. under TU.

\section{Concerns and coverage}

The study has attempted to address the concerns related to: curricular policy direction regarding vocabulary instruction, and characteristics of the words given with focus in the course books. More specifically, the study has covered: linguistic analysis of items, their frequency in general English use, their usefulness for students, and nature of their occurrence in the course books.

\section{Methodology}

After critically studying the syllabus of General English, two course books were consulted: (i) New Generation English (NGE) (Awasthi, Bhattarai, and Khaniya, 2009), and (ii) Academic Vocabulary in Use (AVU) (McCarthy and O'Dell, 2008). Then the words (lemmas) targeted for practice in the exercises of these books and those given in the glossaries of NGE were listed. These items were then analyzed addressing the concerns of study mentioned above.

In determining how frequently the words focused in the course books occur in use, the list of coursefocused vocabulary items was compared against 
some word lists established on the basis of word frequency counts in the contemporary day-to-day English, including:

- Longman dictionary-derived list (2003)

- Collins COBUILD dictionary-derived list (2006)

- Cambridge dictionary-derived list (2008)

- Collins COBUILD dictionary-derived list (2009)

- Oxford dictionary-derived list (2010)

Each of the words in the list of course-focused items was checked in all these frequency-based word lists, to see whether it appeared therein. An item in the list of course-focused words was considered 'frequent' if found in any of the five word lists. Regarding the items' usefulness for B.Ed. students, a word in the course-based list was considered 'more useful' if it could meet one of these 4 criteria: identified as 'frequent'; found in one of the academic vocabulary lists mentioned below; found in one of the defining vocabulary lists below; and met in one of the dictionaries of education listed below.

- Academic vocabulary lists

- Coxhead's academic word list (2000)

- Collins COBUILD academic word list (2009)

- Oxford dictionary-derived academic word list (2010)

- Defining vocabulary lists

- Cambridge defining vocabulary (Procter, 1995)

- Longman defining vocabulary (2003)

- Collins COBUILD defining vocabulary (2009)

- Dictionaries of education

- Rowntree's Dictionary of Education (1981)

- Taneja's Dictionary of Education (1989)

- Wagley and Dhakal's Dictionary of Education (2008)

After determining the usefulness of words focused in the course books, total number of 'more useful' and 'less useful' items was calculated. Finally, the nature of occurrence of the items in the course books was critically studied considering whether they occurred in exercises or glossaries, and whether they occurred once or more times.

\section{Analysis and interpretation}

Within the limitation of the coverage of study, data have been analyzed, interpreted, presented and discussed in the sub-headings that follow.

\section{Focus in the syllabus}

As given in 'course description', vocabulary has been considered as a key component of B.Ed. General English course. Among the five general objectives of teaching this subject, two are related to vocabulary development, which include: "to expand the students' repertoire of general and academic vocabulary", and "to familiarize students with the techniques of enriching vocabulary" (TU/ FOE, 2008).

In addition, specific objectives are mentioned under the different 'contents' of the course, including those related to vocabulary teaching with the aims of enabling students to: "be familiar with the academic vocabulary and use them in a given discourse", and "learn appropriate strategies to enrich their academic vocabulary". Vocabulary contents have also been listed explicitly in the course. Altogether 35 periods (23.3\% time) are allocated for vocabulary out of the total 150 periods per academic year.

For evaluation, $15 \%$ marks are allotted to vocabulary. There is a contradiction regarding the time allotment indicated under 'Contents' on one hand and that under 'Evaluation Scheme and Time Allotment' on the other. The 35 periods given under 'Contents' become $23.3 \%$, while only $15 \%$ time has been mentioned for vocabulary under evaluation scheme. When the course books are thoroughly studied, it is estimated that at least 35 periods are required to adequately address this component.

Out of the three course books recommended in syllabus, two have vocabulary exercises for students: NGE and AVU. The analysis presented hereafter, instead of covering all running words occurred in the course books, is confined to the words presented with focus for learning in these books.

\section{Statistics of words focused for learning}


All the vocabulary items focused in course books (NGE and AVU) have been closely examined from various perspectives; and words are categorized and counted. The statistics of focused words has been presented and discussed below under various sub-headings.

\section{Linguistic considerations}

Having identified the total 'types' of items from the tokens focused in course materials, the words have been further categorized in terms of the word classes they belong to, the number of syllables and letters they contain, and their morphological composition. The result has been displayed in Table 1.

As shown in Table 1, there are altogether 2168 'tokens' of focused items in the two course books, while the 'types' are 1858. The statistical figures presented here draw our attention towards the realities described below.

Word class: Noun, verb, adjective, adverb, preposition, conjunction, and pronoun have occupied the first, second, third, fourth, fifth, sixth and seventh position respectively. More than twothirds of the total items belong to the classes of noun and verb; and $92.9 \%$ of the total focus has been covered by noun, verb and adjective. The share of adverb is found $6.24 \%$, while the remaining three word classes have a negligible share (below $0 \%$ for each).

In the author's calculation based on the count of headwords entered in Oxford Advanced Learner's Dictionary of Current English 2010, about 50.1\%, $23.3 \%, 23.4 \%$ and $2.1 \%$ items are nouns, verbs, adjectives and adverbs respectively. It seems this composition of English vocabulary, more or less, has been reflected in the relative size of the different word classes focused for learning in the course books - whereby noun has got the largest share followed by verb, adjective and adverb.

Word length: Two major factors regarding word length have been considered in the study: number of syllables, and number of letters. As Table 1 indicates, the longest word has 7 syllables ('telecommunication'), while the shortest ones are monosyllabic (e.g. 'age', 'change'). Among the total focused words, $53.5 \%$ have one or two syllables; $25.78 \%$ are tri-syllabic; and the remaining $20.7 \%$ have four or more syllables.

Considering the number of letters, the longest items

[Table 1: Statistics of Focused Words Considering Linguistic Characteristics

\begin{tabular}{|c|c|c|c|c|c|c|}
\hline \multicolumn{3}{|c|}{ Total number of items } & \multicolumn{2}{|c|}{$\begin{array}{c}\text { Categorization by number of } \\
\text { letters }\end{array}$} & \multicolumn{2}{|c|}{$\begin{array}{l}\text { Categorization by morphological } \\
\text { composition }\end{array}$} \\
\hline \multirow{2}{*}{\multicolumn{2}{|c|}{ Tokens }} & \multirow[t]{2}{*}{2168} & $\begin{array}{l}\text { No. of let- } \\
\text { ters }\end{array}$ & Statistics & \multirow[t]{2}{*}{ Polymorphemic } & \multirow[t]{2}{*}{$846(45.53 \%)$} \\
\hline & & & 3 & $31(1.67 \%)$ & & \\
\hline \multicolumn{2}{|c|}{ Repeatedly occurred } & 307 & 4 & $144(7.75 \%)$ & Monomorphemic & $1012(54.47 \%)$ \\
\hline \multicolumn{2}{|c|}{ Types } & 1858 & 5 & $201(10.82 \%)$ & Total & $1858(100 \%)$ \\
\hline \multicolumn{3}{|c|}{$\begin{array}{l}\text { Number of items ('types') by word } \\
\text { class }\end{array}$} & 6 & $280(15.07 \%)$ & \multicolumn{2}{|c|}{$\begin{array}{l}\text { Polymorphemic items categorized by } \\
\text { composition }\end{array}$} \\
\hline Adjective & \multicolumn{2}{|c|}{$439(23.63 \%)$} & 7 & $296(15.93 \%)$ & Compounds & $106(12.53 \%)$ \\
\hline Adverb & \multicolumn{2}{|c|}{$116(6.24 \%)$} & 8 & $257(13.83 \%)$ & Derived & $740(87.47 \%)$ \\
\hline Conjunction & \multicolumn{2}{|c|}{$4(0.22 \%)$} & 9 & $221(11.89 \%)$ & Total & $846(100 \%)$ \\
\hline \multirow[t]{2}{*}{ Noun } & \multirow{2}{*}{\multicolumn{2}{|c|}{$810(43.6 \%)$}} & 10 & $179(9.63 \%)$ & \multicolumn{2}{|c|}{ Categorization by syllables } \\
\hline & & & & & No. of syllables & Statistics \\
\hline Preposition & \multicolumn{2}{|c|}{$9(0.48 \%)$} & 11 & $118(6.35 \%)$ & 1 & $293(15.77 \%)$ \\
\hline Pronoun & \multicolumn{2}{|c|}{$3(0.16 \%)$} & 12 & $73(3.93 \%)$ & 2 & $701(37.73 \%)$ \\
\hline Verb & \multicolumn{2}{|c|}{$477(25.67 \%)$} & 13 & $34(1.83 \%)$ & 3 & $479(25.78 \%)$ \\
\hline Total & \multicolumn{2}{|c|}{$1858(100 \%)$} & 14 & $18(0.97 \%)$ & 4 & 277 (14.91\%) \\
\hline & & & 15 & $3(0.16 \%)$ & 5 & $99(5.33 \%)$ \\
\hline & & & 16 & $1(0.05 \%)$ & 6 & $8(0.43 \%)$ \\
\hline & & & 17 & $2(0.11 \%)$ & 7 & $1(0.05 \%)$ \\
\hline & & & Total & $1858(100 \%)$ & Total & $1858(100 \%)$ \\
\hline
\end{tabular}


are found with 17 letters ('telecommunication', 'misinterpretation'), while the shortest ones have 3 (e.g. 'apt', 'aim'). Altogether $35.31 \%$ focused words are composed of less than 7 letters. The items having 7-10 letters are about $51.3 \%$, while those involving more than 10 letters are $13.4 \%$.

It has been accepted that shorter words are more comfortably learned than longer ones. To quote from Ellis (1994, p. 22), "Monosyllabic words are easier to learn than polysyllabic ones." Ellis and Beaton (1990, p. 568) say, "The longer the FL (foreign language) word, the more to be remembered, the more scope for phonotactic and orthographic variation and thus the more room for error." Laufer (1997b) has reported the findings of Coles (1982) and Phillips (1981) in which word length had a significant influence on the learning of vocabulary among second language learners. Similarly, in another study (Gerganov and Taseva 1982, cited by Laufer, 1997b), one-syllable words were memorized by learners more easily than two-syllable ones. Brown (1997) has concluded that large proportion of long words (7 or more letters) in a reading text may create readability problems.

Thus, it can be speculated that, since there is a large number of polysyllabic words and about twothirds of the focused words are composed of seven or more letters, the overall learning load of these items is high for common students. However, this speculation is yet to be empirically tested among the targeted audience of the course materials.

Word structure: When morphological composition was studied, $45.53 \%$ items were found polymorphemic (e.g. 'overall', 'recently'). The rest $54.47 \%$ are monomorphemic (e.g. 'argue', 'answer'), which are not further divisible into any meaningful constituents.

Out of the 'polymorphemic' items, $12.53 \%$ are compounds, which are built after the combination of short words or free morphemes (e.g. 'furthermore', 'framework'). The rest $87.47 \%$ are derived words, (e.g. 'experimental', 'extension'), that are composed after combining free and bound morphemes.

The matter of whether a polymorphemic word is learned more comfortably or not depends mostly on whether the learners are already familiar with its constituent/s or not. As Laufer (1997b, p. 146) states: "The learner's ability to decompose a word into its morphemes can facilitate the recognition of a new word and its subsequent production." It can be said, in connection with the present study, that though the learning of 'experimental' may not be a problem for the B.Ed. students as its constituents are familiar for them, they can face difficulty in the words like 'castration', as they have never met its constituent root ('castrate') in their previous learning.

\section{Frequency and usefulness}

Addressing the concern of study, an attempt has been made, using the tools mentioned earlier (See: Methodology), to see the frequency of the focused items in English use. Moreover, it has also been attempted to speculate how useful they will be for the students of B.Ed. in their academic pursuit from a broader perspective. Accordingly, the words have been classified into 'frequent' versus 'infrequent' and 'more useful' versus 'less useful' categories. The quantitative figure of this classification is presented in Table 2 .

Table 2: Statistics of Words Considering Frequency and Usefulness

\begin{tabular}{|l|l|l|}
\hline \multicolumn{3}{|l|}{ Frequency in general English use } \\
\hline Categories & $\begin{array}{l}\text { Number } \\
\text { of items }\end{array}$ & Percentage \\
\hline Frequent & 1037 & $55.87 \%$ \\
\hline Infrequent & 821 & $44.13 \%$ \\
\hline Total & 1858 & $100 \%$ \\
\hline Usefulness from a broader perspective \\
\hline Categories & $\begin{array}{l}\text { Number } \\
\text { of items }\end{array}$ & Percentage \\
\hline More useful & 1233 & $66.36 \%$ \\
\hline Less useful & 625 & $33.64 \%$ \\
\hline Total & 1858 & $100 \%$ \\
\hline
\end{tabular}

Altogether $55.87 \%$ of the total items focused for learning have the possibility of occurring frequently in general English use (e.g. 'accident', 'benefit', 'claim'), while the rest $44.13 \%$ are infrequent (e.g. 'abasement', 'amputate', 'brimful'). Interestingly, the items of 'infrequent' category presented with focus for students' learning not only include the rare English words but also those from other languages including Nepali. For example, the words andolan, babu, chhora, ghusyaha, ladang, 
posada, etc. are found in NGE. Among these, andolan, babu, chhora, and ghusyaha are borrowed from Nepali; and these words have occurred in exercise for intensive practice of meaning, which seems unnecessary. The occurrence of words like ladang and posada in glossary, however, can be justified as they help in learners' comprehension of the text, since these are not the words of students' native language.

More than $66 \%$ items are identified to have comparatively a greater usefulness for the students. These words include the 'more frequent' ones as well as the 'defining words', 'academic words' and the words found in the dictionaries of education. All these items have a high potentiality of occurrence, considering the career pursuit of B.Ed. students. Many infrequent items have also been identified as useful for the learners. Such examples include: 'advocacy', 'aggregate', 'coherent', 'explicit', 'generalize', etc. Out of the total items focused in course books, $33.64 \%$ words cannot be considered so useful for the students. Some examples are: 'apartheid', 'condone', 'disdain', 'hammock', 'impotent', 'ominously', etc.

\section{Nature of Occurrence in Course Books}

Regarding the nature of items' occurrence in the students' course books, data have been studied considering these points: overall distribution of the focused items in the two course books, their occurrence in exercise versus glossary, repetition with focus in the books, and distribution of frequent versus infrequent or more useful versus less useful items in books. The results of categorization from these perspectives and calculation of statistical figures thereby have been summarized in Table 3.

As shown in Table 3, $46.66 \%$ of the total focused vocabulary items have occurred in NGE, and the remaining $53.34 \%$ are in AVU. Although AVU contains a greater number of items than NGE, the focus given in NGE is also remarkable considering many other things it has covered for teaching including reading comprehension and writing skill. The table shows that altogether $16.52 \%$ items have occurred more than once with focus, while $83.48 \%$ have been focused just once.

Regarding the frequency of items occurred in NGE alone, it has been found that about two-thirds $(66.09 \%)$ of the words are infrequent in general English use. On the other hand, $75.08 \%$ of the items focused for practice in AVU are frequent. From the point of view of usefulness, $40.83 \%$ of the items focused in NGE are in the 'more useful'

Table 3: Statistics of Words Considering their Occurrence in Course Books

\begin{tabular}{|c|c|c|c|c|}
\hline \multicolumn{3}{|c|}{ Occurrence in course books } & \multicolumn{2}{|c|}{$\begin{array}{l}\text { Distribution of frequent vs. infrequent items } \\
\text { in AVU }\end{array}$} \\
\hline \multicolumn{2}{|l|}{ NGE } & $867(46.66 \%)$ & Frequent & $744(75.08 \%)$ \\
\hline \multicolumn{2}{|l|}{ AVU } & $991(53.34 \%)$ & Infrequent & $247(24.92 \%)$ \\
\hline \multicolumn{2}{|l|}{ Total } & $1858(100 \%)$ & Total & $991(100 \%)$ \\
\hline \multicolumn{3}{|c|}{ Repetition in books } & \multicolumn{2}{|c|}{$\begin{array}{l}\text { Distribution of more useful vs. less useful items } \\
\text { in NGE }\end{array}$} \\
\hline \multirow[t]{3}{*}{ Repeated } & NGE & 75 & More useful & $354(40.83 \%)$ \\
\hline & AVU & 232 & Less useful & $513(59.17 \%)$ \\
\hline & Sum & $307(16.52 \%)$ & Total & $867(100 \%)$ \\
\hline \multicolumn{2}{|l|}{ Unrepeated } & $1551(83.48 \%)$ & \multicolumn{2}{|c|}{$\begin{array}{l}\text { Distribution of more useful vs. less useful items } \\
\text { in AVU }\end{array}$} \\
\hline \multicolumn{2}{|c|}{ Total } & $1858(100 \%)$ & More useful & $877(88.5 \%)$ \\
\hline \multicolumn{3}{|c|}{ Distribution of frequent vs. infrequent items in NGE } & Less useful & $114(11.5 \%)$ \\
\hline \multicolumn{2}{|l|}{ Frequent } & $294(33.91 \%)$ & Total & $991(100 \%)$ \\
\hline \multicolumn{2}{|l|}{ Infrequent } & $573(66.09 \%)$ & \multicolumn{2}{|c|}{ Occurrence in glossary versus exercise } \\
\hline \multicolumn{2}{|l|}{ Total } & $867(100 \%)$ & Glossary & $379(20.4 \%)$ \\
\hline \multirow{3}{*}{\multicolumn{2}{|c|}{ 10101 }} & & Exercise & $1394(75.03 \%)$ \\
\hline & & & $\begin{array}{l}\text { Glossary plus ex- } \\
\text { ercise }\end{array}$ & $85(4.57 \%)$ \\
\hline & & & Total & $1858(100 \%)$ \\
\hline
\end{tabular}


category, and the rest $59.17 \%$ are 'less useful'. The figure shows a drastically different situation in the case of AVU, whereby $88.5 \%$ and $11.5 \%$ items included in the book for practice are found 'more useful' and 'less useful' respectively.

Considering the items' occurrence in exercise versus glossary, $20.4 \%$ of them are found only in the glossaries given in NGE in the end of reading texts with the words' meanings/definitions. Such words include the frequent items (e.g. 'initial', 'mighty', 'nervous', 'sweat') as well as very rare ones (e.g. 'cynical', 'dabble', 'incapacitate', 'juxtaposition'). Likewise, $75.03 \%$ words have been focused in various kinds of vocabulary exercises in the two books. But the words presented in both ways (glossary and exercise) are limited just to $4.57 \%$ (85 in number). Out of these items occurred in glossary as well as exercise, $35(41.2 \%)$ have been found 'more useful' (e.g. 'ambiguity', 'detention', 'rescue'), while the remaining $50(58.8 \%)$ are 'less useful' (e.g. 'gulp', 'supersede', 'rickety').

Overall, the following remarks can be furnished after the study of data presented in Table 3 :

- The fact that nearly $80 \%$ of the focused items have occurred in exercises has the indication that the course designers have the intention of involving the learners in practicing a large quantity of items for the enrichment of their word-meaning knowledge. It seems the rest $20 \%$ are just meant for assisting the learners understand the reading text in which the items have occurred.

- Whether the vocabulary items focused for practice are considered in terms of their frequency in general English use or usefulness for the students studying B.Ed., AVU seems to have addressed learners' needs much better; and the items focused for study therein are more relevant for students' enrichment of English in their academic pursuit, compared to the ones included in NGE.

- Words' frequency and usefulness have not been considered so seriously in the preparation of lessons included in NGE, as reflected in the over-emphasis on less useful items therein.

- Although the idea of presenting the rare ('less useful') English words in glossary is justified considering the need to facilitate the readers in comprehension, occurrence of these items in exercises can hardly be justified, as they are not essential for the learners' normal English use.

\section{Usefulness of items provisioned in glossary and exercise}

A research thirst could be a further exploration to see what amount of vocabulary stock focused through exercises in the course books is 'more' or 'less' useful, and whether there are any 'more useful' items presented just in glossary. After studying all the items with these curiosities, the statistical figure has been presented in Table 4 .

Table 4: Occurrence of Less Useful and More Useful Words in Glossary vs. Exercise

\begin{tabular}{|l|l|}
\hline \multicolumn{2}{|l|}{ Less useful } \\
\hline Exercise (or glossary + exercise) & $352(56.32 \%)$ \\
\hline Only in glossary & $273(43.68 \%)$ \\
\hline Total & $625(100 \%)$ \\
\hline More useful & $1133(91.86 \%)$ \\
\hline Exercise (or glossary + exercise) & $100(8.14 \%)$ \\
\hline Only in glossary & $1233(100 \%)$ \\
\hline Total &
\end{tabular}

Out of the total less useful items focused in the course books, $56.32 \%$ have occurred in exercises; and the remaining $43.68 \%$ are found in glossaries. The focus given on the vast number of less useful vocabulary items through exercises seems unnecessary. Such words include: 'amputate', 'anaconda', 'depreciate', 'frowsy', 'ramshackle', 'transcend', etc.

Altogether $91.86 \%$ of the total more useful items have occurred in exercises. Relatively, useful words found just in glossaries (without being focused for learners' practice through exercises) are few, just limited to those demonstrated in Table 5 .

These items can be classified into two groups from the point of view of the students' background of English language learning: the ones they encounter for the first time at B.Ed., and those occurred in the course materials of their previous schooling. Words like 'conservancy', 'integration', 'notorious' etc. are new to the students (unless they have found the items elsewhere), while the 
Table 5: More Useful Items Occurred in Glossary but not Exercises

\begin{tabular}{|c|c|c|c|c|c|}
\hline accommodating & conservancy & endure & integration & performance* & starve + \\
\hline adjunct & courtesy* & entity & intensifier & persuade* & sweat* \\
\hline advocacy & critic* & ethnicity & intimate & predominantly & terminal* \\
\hline anecdote & crush* & exceedingly* & invasion* & probation & terrified* \\
\hline apathy & crystal & exile* & isolated + & proclaim & theological \\
\hline appliance* & cynical & fantasy & mall & prompt & trademark \\
\hline appreciable & daydream & fascinating* & mighty & rebel + & trumpeting \\
\hline archaeologist* & delicate* & formidable & mimic* & regret* & unidentified \\
\hline architect* & departure* & foster & mummy* & repertoire & \begin{tabular}{|l|} 
vaguely \\
\end{tabular} \\
\hline bare* & discriminatory & front & mutter & resemble & variance \\
\hline cemetery & disguise & funeral* & nervous* & rock* & venture \\
\hline cliff* & dock* & gesture* & neutral & ruined* & viable \\
\hline cling & dread* & grab* & notorious & sake* & vulnerable \\
\hline collapse + & dreadful* & holistic & novice & scramble* & woods* \\
\hline conference & elegant* & homogenous & orderly & semantic & wrecked* \\
\hline confined* & elite & hypocrisy & overlook & solitary* & \\
\hline confrontation & embarrass + & implement* & paradigm & stare* & \\
\hline
\end{tabular}

Note: * occurred previously in the course materials at school level

+ occurred with focus in PCL compulsory English

items like 'sweat', 'invasion', 'departure', etc. have been taught in the school course books. In the same way, some other words including 'isolated', 'starve', 'collapse' etc. have occurred for students' practice in the Compulsory English course books of Proficiency Certificate Level (PCL) under TU (Luitel, 2006); and many students studying the B.Ed. course during the preparation of this article have practiced them. (However, as PCL has been phased out from TU since 2067-68 B.S., no student in future will have practiced these items with focus prior to his/her enrolment in B.Ed.) Thus, out of the words given in Table 5, sixty are logically speculated to be unfamiliar to most of the students, despite being very useful. Therefore, they deserve special attention in exercises.

\section{Conclusion}

It seems the focus offered to vocabulary component in B.Ed. General English course is reasonably high considering the emphasis given in the objectives of syllabus and the quantity of items incorporated in the exercises of course books, though the time allotted for this component in teaching is insufficient.

Overall, frequent vocabulary items focused for learning in the course books are greater than infrequent ones; and about two-thirds of the focused words are useful while the remaining one-third are not so useful for the students. Items of 'infrequent' category presented with focus for learning not only include the English words but also those from other languages including Nepali. Such items have occurred even in exercises. From the point of view of frequency as well as usefulness of words, AVU seems to have offered much more appropriate lexical content than NGE. It seems frequency and usefulness of items have not been considered so seriously while designing the exercises given in NGE.

\section{Acknowledgement}

The author is grateful to University Grants Commission/ Nepal for the support to conduct a research (provided through Faculty Research Grants Award) on which this paper is based.

\section{The Author}

Binod Luitel, a life member of NELTA, is an Associate Professor of English Education in Tribhuvan University (Nepal). $\mathrm{He}$ has got $\mathrm{Ph} D$ in language curriculum, published several papers in journals including Journal of NELTA and Indian Linguistics, and attended and delivered presentations in many national-international academic events. His areas of interest include: teacher training/development, curriculum, material development, vocabulary, learner hierarchy, cooperative learning, and classroom-based pedagogic innovation. He 
has been teaching in the university for 16 years; and now he is also involved as a researcher in Research Centre for Educational Innovation and Development (CERID) under the university.

\section{References}

Adolphs, S. and Schmitt, N. (2003). Lexical coverage of spoken discourse. Applied Linguistics 24(4). pp. 425-38.

Awasthi, J.R., Bhattarai, G.R., and Khaniya, T.R. (Eds.).(2009). Newgeneration English. Kathmandu: Vidyarthi Prakashan.

Brown, J.D. (1997). An EFL readability index. University of Hawaii working papers in ESL 15.2. pp. 89-119.

Carter, R. (1987a). Is there a core vocabulary? Some implications for language teaching. Applied Linguistics 8(2). pp.178-93.

Carter, R. (1987b). Vocabulary and second/foreign language teaching. Language Teaching 20(1). pp. 3-16.

Coxhead, A. (2000). A new academic word list. TESOL Quarterly 34(2). pp. 213-38.

Ellis, N.C. and Beaton, A. (1990). Psycholinguistic developments of foreign language vocabulary learning. Language Learning 40.1. pp. 559-617.

Ellis, R. (1994). Factors in the incidental acquisition of second language vocabulary from oral input: A review of essay. Applied Language Learning 5.1. pp. 1-32.

Heinle Cengage Learning and Harper Collins. (2009). Collins COBUILD advanced illustrated dictionary. Glasgow: Author.

Hornby, A.S. (2010). Oxford advanced learner's dictionary of current English. Oxford: Oxford University Press.

Hu, X.Q. and Kelly, P. (2004). Helping the language learner overcome the hurdles posed by vocabulary, with particular focus on the Chinese learner of English. The English Teacher: An International Journal 7.1. pp. 18-33.

Johnstone, R. (2003). Annual review of research. Language Teaching 36(3). pp. 165-89.

Kučera, H. and Francis, W.N. (1967). Computational analysis of present-day American English. USA: Brown University Press.

Laufer, B. (1997a). The lexical plight in second language reading: Words you don't know, words you think you know, and word you can't guess. In J. Coady and T. Huckin (Eds.) Second language vocabulary acquisition: A rationale for pedagogy. Cambridge: Cambridge University Press. pp. 2034.

Laufer, B. (1997b). What's in a word that makes it hard or easy: Some intralexical factors that affect the learning of words. In N. Schmitt and M. McCarthy (Eds.) Vocabulary: Description, acquisition and pedagogy. Cambridge: Cambridge University Press. pp. 140-55.

Luitel, B. (2006). A frequency-based analysis of targeted vocabulary items in PCL (I Year) Compulsory English under T.U. A research report submitted to Research Division/Tribhuvan University.

McCarthy, M. (1990). Vocabulary. Oxford: Oxford University Press.

McCarthy, M. and O'Dell, F. (2008). Academic vocabulary in use. Cambridge: Cambridge University Press.

McGregor, A.K. (1989). The effect of word frequency and social class on children's reading comprehension. Reading 23(2). pp. 105-15.

Meara, P., Lightbown, P.M. and Halter, R.H. (1997). Classrooms as lexical environments. Language Teaching Research 1(1). pp. 28-47.

Nation, P. (Ed.). (1994). New ways in teaching vocabulary. Alexandria: Teachers of English to Speakers of Other Languages, Inc.

Nation, P. and Waring, R. (1997). Vocabulary size, text coverage and word lists. In N. Schmitt and M. McCarthy (Eds.) Vocabulary: description, acquisition and pedagogy. Cambridge: Cambridge University Press. pp. 6-19.

Pearson Education Limited. (2003). Longman dictionary of contemporary English. Harlow: Author.

Procter, P. (1995). Cambridge international dictionary of English. Cambridge: Cambridge University Press.

Read, J. (2000). Assessing vocabulary. Cambridge: Cambridge University Press.

Richards, J.C. (1974). Word lists: Problems and prospects. RELC Journal 5.2. pp. 69-84.

Richards, J., Platt, J., and Weber, H. (1985). Longman dictionary of applied linguistics. Harlow: 
Longman.

Rowntree, D. (1981). A dictionary of education. London: Harper \& Row Ltd.

Sinclair, J. and others. (Eds.). (2006). Collins COBUILD advanced learner's English dictionary. Glasgow: Harper Collins.

Taneja, R.P. (1989). Dictionary of education. New Delhi: Anmol Publication.

Tribhuvan University, Faculty of Education (TU/ FOE). (2008). Revised Courses of Three Year Bachelor of Education for First Year.
Wagley, M.P. and Dhakal, M.P. (2061-i.e. 2008). Dictionary of education. Kathmandu: Ratna Pustak Bhandar.

Walter, E. and others. (2008). Cambridge advanced learner's dictionary. Cambridge: Cambridge University Press.

Wang, M. and Koda, K. (2005). Commonalities and differences in word identification skills among learners of English as a second language. Language Learning 55(1). 71-78. 